\title{
NUMERICAL SIMULATION OF MASS MOVEMENT USING REMOTE SENSING DATA FOR NARENDRA NAGAR -UTTARAKHAND
}

\author{
SUSHIL KUMAR ${ }^{1}$, VIPIN ${ }^{2}$, AMIT TYAGI ${ }^{3}$ \& AKANKSHAGUPTA ${ }^{4}$ \\ ${ }^{I}$ Technical Officer-DIPR, DRDO \\ ${ }^{2}$ Professor -Delhi Technological University, Delhi \\ ${ }^{3}$ Scientist-CFEES, DRDO \\ ${ }^{4}$ Scholar- Delhi Technological University, Delhi
}

\begin{abstract}
Narendra Nagar is a small-town on National Highway-34it is around at distance 49 km from Dehradun, towards the north $30.17^{\circ} \mathrm{N}$ eastern $78.30^{\circ} \mathrm{E}$ extremity of slight mountain area in the district of Tehri Garhwal, Uttarakh and. Every year the rainy season brings extreme landslides on this highway, leading to many casualties as well as disruption and destruction of public transport. The present project objective to find the outline of these landslides and thereby to make a simulation model to facilitate the safe movement on this highway based on Remote Sensing data of Narendra NagarRishikesh by using RAMMS software. The working models of RAMMS are based on fluid friction law- 'voellmy'. This working model further classified into two frictional resistances: Frictionaldry-coulomb-type [M] and Friction viscousturbulent-type [ $\xi$ ]. RAMMS input data is satellite image with very high pixelated and converted into DEM(Digital Elevation Model $5 \mathrm{~m}$ ]compatible with model. When simulated run they provide flow information like velocity, height, Momentum \& Pressure of debris flow path. The maximum velocity is $29.62 \mathrm{~m} / \mathrm{s}$ \& maximum height $32.58 \mathrm{~m}$. The output parameter can be used to find out run-out zone for debris flow in and around Narendra Nagar.

KEYWORDS: Debris Flow, Numerical Simulation, RAMMS, Narendra Nagar
\end{abstract}

Received: Jun 06, 2020; Accepted: Jun 26, 2020; Published: Aug 31, 2020; Paper Id.: IJMPERDJUN2020972

\section{INTRODUCTION}

Landslides are influential geologic actions that occur unexpectedly and cause destruction in men living zones with unbalanced mounts, slopes and bluff sides. A landslide is geological process mainly consist of three mixtures rock, artificial fill and soil with support of gravity forces and movement down a slope. However, many activities can generate landslides, including slowly removing of rocks, volcanic action, earthquake and material erosion, especially during rainy seasons. The main driving force causing these landslides are the gravitational forces which act toward the center of the earth, thus causing any unstable structures present on sloping surface to move downwards with such a force that leads to further different motions in the process, causing devastation and destruction of life as well as natural resources. Statistically it is calculated that about 450 casualties and infrastructure worth amount Rs 350cores are lost every year due to landslide (GSI 2020). Generally, three methods mostly now days uses for prediction about run-out distance: Empirical Statistical approach, Analytical approach and Numerical Analysis approach (J.Krusic et al., 2018). Finding flow path with very high accuracy and characteristic applied numerical simulation analysis method (tsai et al., 2011). The numerical method is very scientifically approach for analyzed constraint of the movement of the debris flow and finished terrains topographic area. (chem, lee, 2004). However, this method can be finding flow path with impact pressure at every point and flow depth these 
characteristics values are depend upon maximum intensity and can be joined with quantifiable risk valuation which works on vulnerability functions. Engineering Branch of Fluid mechanics applying in the numerical analysis method. This method are works on Law of conservation mass, energy and momentum equation for model of dynamic continuum. This law of conservation equation defines the dynamic motion of debris flow and further it is made compatible with flow depth and new method developed those know as depth averaging method for analysis. Here this dynamic model use in two dimensions Firstly 1-D model: In this debris flow in only one longitudinal dimension with only pre-defined cross section of single width. Second 2-D models: in this model debris flow in two directions, plan surface which consider as a topography and their cross-section area. Engineering branch Rheology is study about deformation and flow of matter this also describe models of dynamic and behaviors of frictional for debris flow. Accuracy finding in rheology branch used modelling of dynamic continuum theory (Rickenmann,2005).In rheology branch for finding flow parameters used dynamic models which are works on Frictional resistance, this another term use as a 'Voellmy' that is called frictional-turbulent resistance (Voellmy,1955):Assessing various parameters of debris flow run-out and their intensities (height, velocity, pressure and momentum) and these model plays very important role in estimating hazards with connected losses related elements due to mess flow. The team of Swiss Federal Institute for Snow Avalanche Research (WSL/SLF) was developed RAMMS (Rapid Mass Movements) software modelling package which works on dynamic numerical analysis, starting time they use snow avalanches model (Buhler et al., 2011; Fischer et al., 2012).However, this model was used many researches in their study for calculations parameters of debris flow mass movement flow (Kowalski, 2008), rock avalanches (Schneider et al., 2010) and lahars (Quan Luna, 2011).This model capability to calculate debris flow parameters like velocities, flow height, run-out and sand impact pressure in domain of 2-D as well as in 3-D.Bartelt et al. 1999 was discussed debris flow model in the form of quasi one-dimensional. RAMMS software package works on continuum model which obey Voellmy-Salm fluid flow (Salm, 1993) and hydraulic-based on fluid flow law 'Voellmy' defines the debris flow of depth-average analysis continuum model (Voellmy,1955).Frictional flow resistance can be split into two categories dry-Coulomb( $\mu$ ) and a viscous resistance turbulent $(\xi)$ friction. This two parameter are responsible for behaviors of the debris flow and resistance prevent for quicker moving flow of the turbulent flow ( $\xi$ ) (J.Krusic et al., 2018).

\section{STUDY AREA}

Narendra Nagar is located at $30.17^{\circ} \mathrm{N}, 78.30^{\circ} \mathrm{E}$. It has an average elevation of 1,326 metres which shown highly hilly terrain area and they situated on Rishikesh-tehri National Highway. Narendra Nagar area are $49 \mathrm{~km}$ from the capital of the Uttarakhand towards zone of north east. 


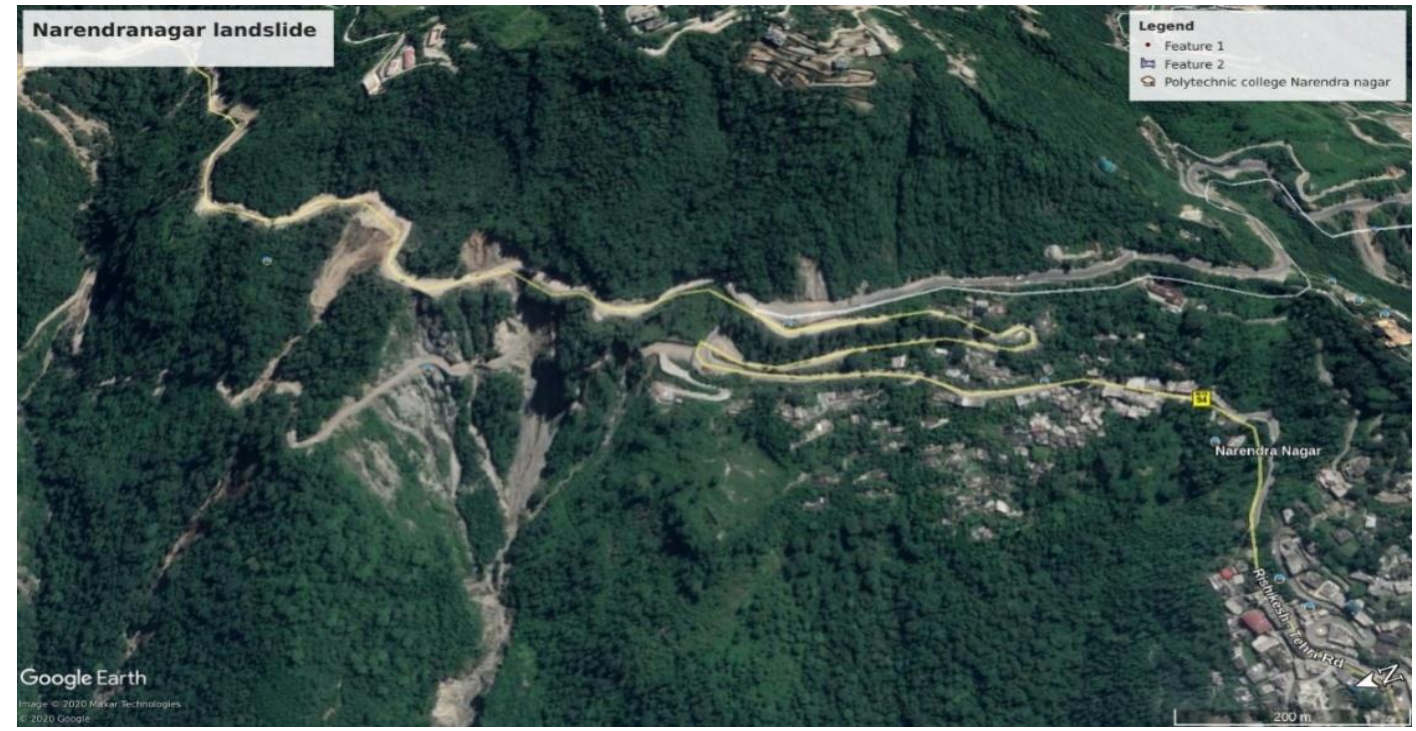

Figure 1: Narendra Nagar Valley (Google Map India).

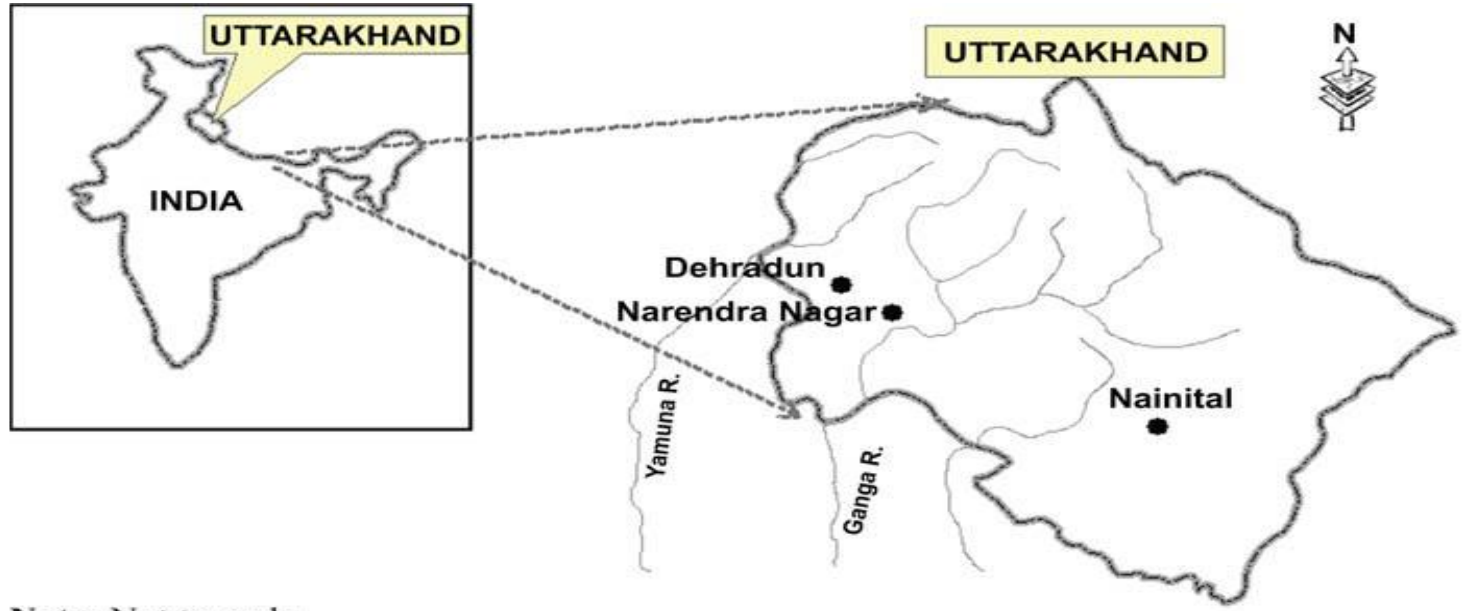

Note: Not to scale

Figure 2: Location Map of Study Area.

\section{METHODOLOGY AND INPUT DATA}

Total troubling impact due to high movement moving of debris flow observed in this study of numerical simulation method around Narendra Nagar. In RAMMS input is satellite image with very high Pixelated and converted into DEM (Digital Elevation Model 5m] compatible with model and providing flow modelling parameters. After finding these parameters next step in modelling is used electronic direct shear testing equipment for performed and validated these parameters.

\section{Satellite Data Used}

In this study used remote sensing data which captured by LISS-IV (Resources at 2) on dated 25 Aug 2018 and Cartosat-2 high digital images on26 Aug 2018 after disaster happen which was be analysed. DEM and LISS (Resourcesat-1) data used in RAMMS with support of Google images along with additional topography data from SRTMDEM can also referred during study. 


\section{Model Input Data}

\section{A). Digital Elevation Model}

RAMMS software works on DEM (Digital Elevation Model) data. Basic input for simulation drive is required of topographic element like slope and elevation which are high-longitudinal-resolution image, release area, and release volume to describe the debris front zone and vital data about friction and topographic parameter depended geo-mechanical characteristic. This information about friction is role play very important for simulation run. The debris flow movement path and their deposition zone in this system will be controlled through the elevation, slope, velocity and pressure. In this reference, a very details parts of DEM are mandatory with high resolution spatial which purpose of define release area in the process. Cartosat-1 DEM with their spatial resolution is 5m used in this study. RAMMS software simulation run only pre-defined cluster data like ASCII X, Y, Z and ESRI ASCII Grid no other input support.

In parallel topographical map in the same time also digitized for developing a DEM in the format of ArcGIS 10.0 (C) ESRI) by using raster tool with the help of topo tool in 3 dimensional predications. After that both results were compared first contours developed by Cartos at DEM and second developed through topographical maps for purpose of numerical simulation output data. Additional, in the modelling of debris flow two input were inserted which can be give important information about initial condition as well as release information about simulation, 1) Release area of debris 2) Hydrograph information. At the starting situation of a simulation of debris flow can be selected in the region of the debris which depend upon type of debris. But in this study release area was chosen because of this are convenient to differentiate between debris flow path unchannelized and channelized. However, the unchannelized debris flow was used in RAMMS for condition of hillslope and narrow landslides. Narendra Nagar satellite image are validated and observed both unchannelized and channelized flow in their path. In simulation of RAMMS, minor debris flow path is unchannelized, it is significant to identify the release area with provided starting height, they was released as a block (Rickenmann et al. 2006).In this study, release area were selected for specified landslide and same fixed over the DEM image. Almost matching observation of domains and assumed debris flow within the restricted areas. This calculation was similarly explained over DEM seeing the probable extreme 3-D range of runout of debris flow.

\section{B). Frictional Parameter}

Numerical simulation model of RAMMS is works on parameters of rheological they consist of slope and same resultant of slope of shear strength. This method is further categorised into two frictional resistance parameters: a dry-Coulomb ( $\mu$ ) and viscous-turbulent $(\xi)$. First frictional resistance is associated for functional of normal stress, second frictional resistance linked with drag velocity-squared. The debris flow total value of frictional resistance $\mathrm{S}(\mathrm{Pa})$ is calculated though following equation $\mathrm{S}=\mu$ phgcos $(\varnothing)+(\operatorname{\rho gU} 2) / \xi$.

In above equation parameter is $\hat{\beta}$ (density),(H) flow height, $(\mathrm{g})$ gravitational acceleration, $(\varnothing)$ the slope angle, (U)flow velocity of debris flow (Salm et al., 1990).Constraints $\mu$ and $\xi$ in this equation are two major input.Further $\mu$ is calculated through friction law that $\mu=\tan \varnothing$, where $\varnothing$ is the internal resistance angle which can be find out by experiment. But here determination of the internal friction angle and c (consistency)through direct shear test instrument the samples of soil collected by from Narendra Nagar.Wide range of materials involved in numerical simulation of debris flow due to this major problem is outcome for selection of frictional constraints, to avoid these problems using many simulations run with uses of different constraint of frictional resistance parameter of RAMMS for their calibration and input value are match as 
actual occurrence data. At last many simulation of the result with assessment data, used for observation best simulation results of frictional resistance values (Sosio et al.,2008). In this study various values coefficient of friction combination used for many simulations run. A wide series value was input during observation for finding ideal frictional value. In the simulation, range 0.05 to 0.4 dry friction coefficient and range 100-450 m/s2 viscous turbulent flow used input in RAMMS. Meanwhile other constraints during simulation were kept constant: material density is $2000 \mathrm{~kg} / \mathrm{m}^{3}$, momentum percentage, earth pressure coefficient and height. Subsequently, the result of debris flow is total run-out distance and actual flow path of aerial ranges confirmed by simulation and these results are confirmed by high resolution image captured through remote sensing data by field data.

In simulated of debris flow synchronized around $92 \%$ (pixel wise) in these were used value actual event is $\mu(\mathrm{Mu})$ $=0.2$ and $\xi(\mathrm{Xi})=200 \mathrm{~m} / \mathrm{s} 2$, for final investigation. In value of dry friction coefficient, it was detected friction coefficient $\mu$ $(\mathrm{Mu})$ is inversely proportional with run out distance. On the additional we are observed $\xi(\mathrm{Xi})$ is independent of the run -out distance and to make smoother of run-out distance by increase $\xi(\mathrm{Xi})$ value.

\section{C). Shear Strength Parameter and Validation of the Simulator}

Demonstrator debris flow materials sampled collected from the base of the flow and analyzed in Electronic machine (Model No. AIM 104-2kN, Make Aimil Ltd., New Delhi)direct shear testing used for finding parameter that is shear strength at Indian Institute of Remote Sensing, Dehradun. At the time of analysis many saturations level value came, but there was considered maximum saturation values those was best in the experiments. The value of shear strength was tested at normal load with considered value $0.20,0.55$, and $1.1 \mathrm{kgf} / \mathrm{cm}^{2}$ resultant values parameter of shear strength measured at the point of failures. When fluctuating of parameter during simulation of debris flow created problem, due to this very difficult to controlled fixed friction parameter in simulation. During simulation we was observed that debris flow in the RAMMS use only one phase model, they cannot be differentiated between solid and fluid phase, and considered the model is a bulk flow of mass. Consequently, in the debris flow case frictional resistance constraints always varied so it ensures appropriate match flow of debris path. It is very difficult to obtain same flow in the many events because of their composition is different. Due to this circumstance very much difficult for value of frictional resistance parameter of calibration. Therefore, many simulations run with different frictional resistance values in each simulation and input parameter due to this observation were find favorite results. After obtained these result from simulation were authenticated with available event data, for final analysis chosen very accurate simulated resultant in study (Sosio et al. 2008).

\section{RESULT \& DISCUSSION}

In output of RAMMS using debris flow as a model is giving many information about structure out of these main four parameters momentum, velocity, height, and pressure was considered for further evaluation about landslide impact. They also providing information in 2-D and 3-D about debris flow structure profile and specified regions every point as per desire. Out of result in RAMMS two are very important role for defining aerial extent area and blockage of existing road due to flow first, debris flow run -outdistance secondly height of flow. As per result of debris flow simulation maximum height $\left(\mathrm{h}_{\text {max. }}\right) 32.58 \mathrm{~m}$ at starting simulation and $5.43 \mathrm{~m}$ at end of simulation as these result show at the starting time release area height too high but after flow passage height is decreased near run out zone (Fig. 3). The velocity value is $14.81 \mathrm{~m} / \mathrm{s}$ reached at mid-way of the flow and their profile is weave shape due to this velocity was fluctuating in the process. At the starting of simulation when release the area velocity attains is maximum value is $\left(\mathrm{V}_{\max }\right.$. $) 29.62 \mathrm{~m} / \mathrm{s}$ after moving the debris they decreased is value about $4.94 \mathrm{~m} / \mathrm{s}$ near last movement of debris (Fig 4).Another parameter momentum in the 
simulation continuously decreased from starting to ending of the debris flow process at starting near release area maximum momentum value is $\left(\mathrm{m}_{\text {max. }}\right) 469.57 \mathrm{~m}^{2} / \mathrm{s}$ and near run out zone value is $78.26 \mathrm{~m}^{2} / \mathrm{s}$ (Fig. 5). Last parameter is pressure this are depends upon the profile of velocity in simulation when changing value of velocity, we observed in the simulation pressure abruptly change the value of pressure maximum ( $\mathrm{P}_{\text {Max. }}$ ) $754 . \mathrm{KPa}$ reached at starting there also velocity is also very high near release area (Fig.6).As above results of numerical simulation model show very important play role for observation about actual debris flow in the hilly area and disaster during rainy seasons. This study helps for prediction about losses in future and remedial from debris flow in terrain area as per result of RAMMS output value easily understanding the behaviour and parameter value of debris flow total run -out zone and slope stability of debris. However, this work is very significant role natural event in the mountain hilly areas and their output match with numerical simulation in Laboratory for observation. The result of RAMMS simulation very important role in engineering like development of dams in hilly area and pipe line and remedial measured before contraction activity with slope protection. Mixing of simulation modelling of 3-D with wide range of landslide mapping resultant is providing actual understanding of debris flow cause and their remedial observation for the investors. This model not only providing consistent simulation outcomes but also well known the effectiveness and flexibility of wide range deteriorating of disaster event due to natural

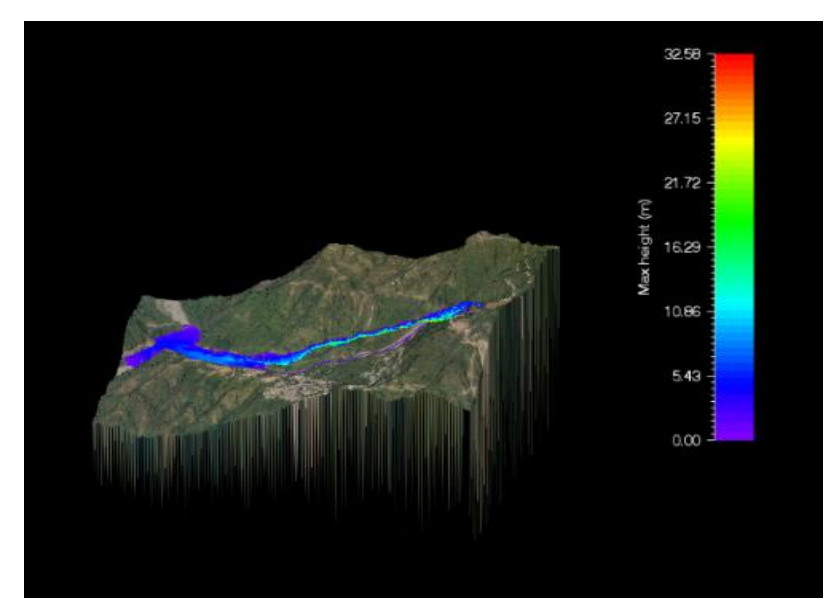

Figure 3: Max.Height.

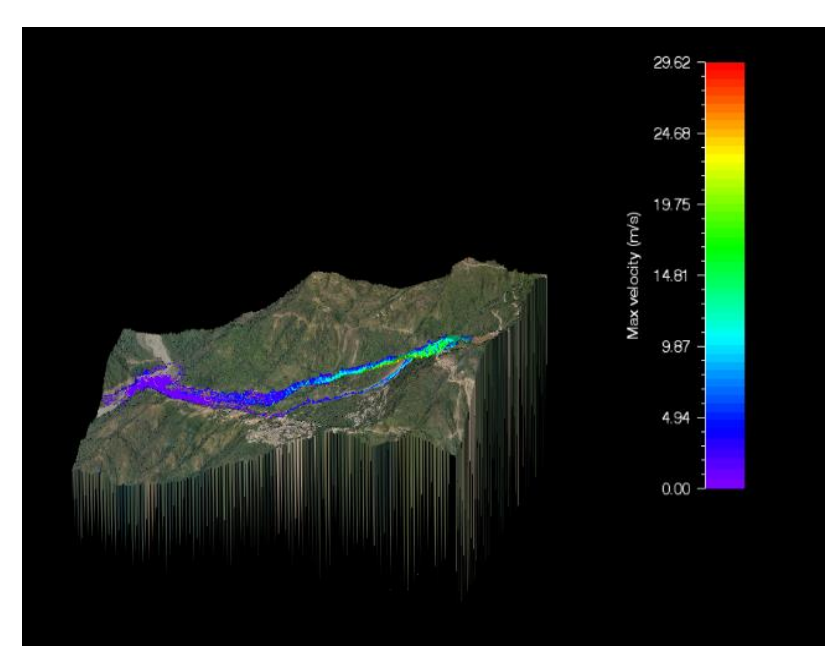

Figure 4: Max. Velocity. 


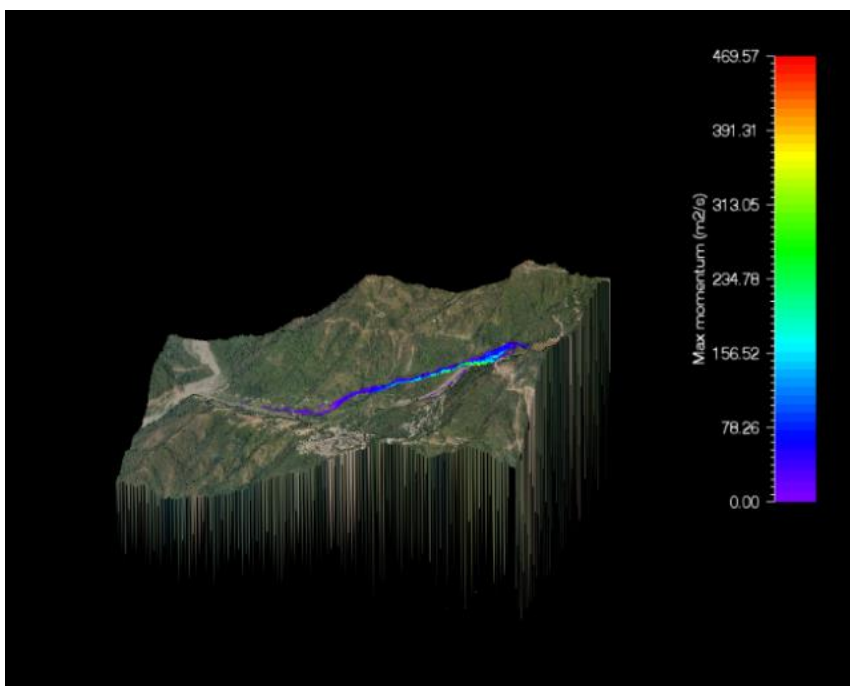

Figure 5: Max. Momentum.

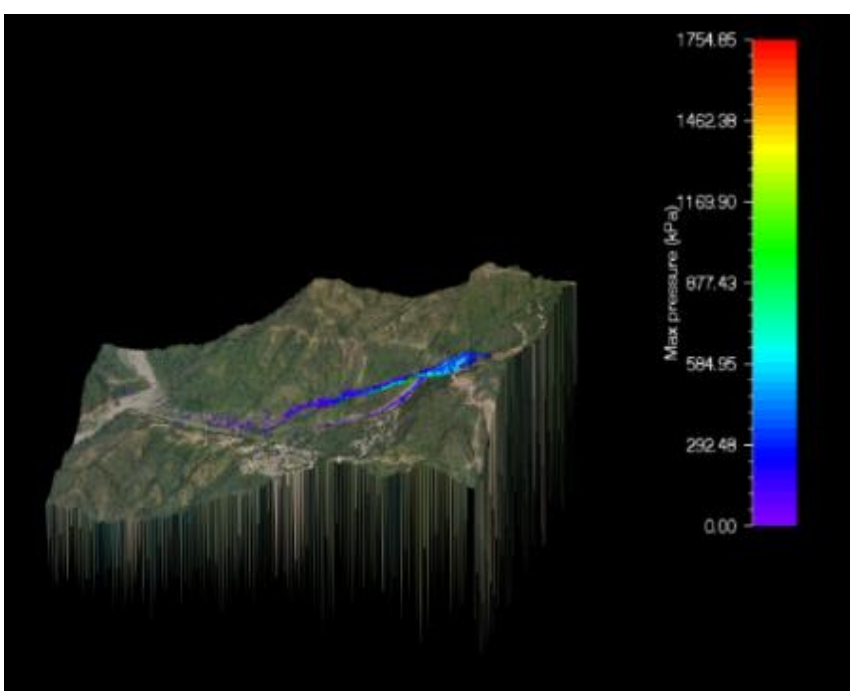

Figure 6: Max. Pressure.

\section{CONCLUSIONS}

High resolution image captured by satellite and converted into DEM for analysis of their parameter in RAMMS, providing 3-Dimenstional debris flow modelling very useful results. In this study first run simulation of Narendra Nagar debris flow successfully and providing resultant as height, velocity, momentum and pressure with the help of input high pixel satellite image data of this area. After that, give inside information about disaster and their values. This study is concluded about numerical simulation of Narendra Nagar modelled providing with satisfaction parameter of debris flow of run-out area. The height of the debris near run-out zone or end of movement is about $5.43 \mathrm{~m}$ the height is decreased because of slope value near run-out is very less as compared release area location. However, this value is on safe zone and concluded that the dams easily captured the run-out and withstand their impact thrust if dam's height little more as compared the run-out zone height. This study represented rough assessment about slope and run-out zone for development of dams in landslide areas and their remedial. In result of simulation velocity and momentum will be providing clear picture about design parameter of dams near landslide area and remedial. Further in simulation model improvement output, effect of mass on route of flow which make impact on rheology side-wise and pressure of hole of soli and erosion. As result of side channel and route cannot be included therefore, actual output always model parameter is better safe side. Moreover, model of 
simulation parameter resultant compares as well as validated previously study. In these references, the RAMMS providing input parameter play important role because this parameter would be generated effect in modelling of simulation. Validated the simulation parameter with the help of collected sample from actual event was carried out in the form of frictional resistance characteristic and shear strength. In this respect to get actual data from field, in this study recommended to accumulate information of debris as earliest at end of disaster in field.

\section{REFERENCES}

1. Bartelt, P., Salm, B., Gruber, U.,(1999).Calculating dense-snow avalanche runout using a

2. voellmy-fluid model with active/passive longitudinal straining. Journal of Glaciology 4 (150),

3. $242-254$

4. Chen H. and Lee C.F.,2000. Numerical simulation of debris flows. Canadian Geotechnical Journal, 37: 146-160

5. GSI (2020), Geological Survey of India, available at www.portal.gsi.gov.in, accessed

6. on January 2020.

7. J. Krusic.,B.,Abolmasov.,M. Marjanovicand D. Djuric., (2018), Numerical modelling in RAMMS - Selanac debris flow, Second JTC1 Workshop on Triggering and Propagation of Rapid Flow-like Landslides, Hong Kong 2018.

8. Kowalski, J., (2008). Two-phase debris flow modeling. Ph.D. thesis, Eidgenössische Technische Hochschule Zürich, ISBN 3866645244.

9. M. Christen, J. Kowalski, \& P. Bartelt (2010), RAMMS: Numerical simulation of dense snow avalanches in three-dimensional terrain, Cold Regions Science and Technology 63 (2010) 1-14

10. Quan Luna B, Blahut, J, van Westen, C.J., Sterlacchini, S., van Asch T.W.J. and Akbas, S.O., (2011), The application of numerical debris flow modelling for the generation of physical vulnerability curves. Natural Hazards and Earth System Sciences 11, pp 2047-2060.

11. Rickenmann, D. and Koch, T.(1995), Comparison of debris flow modelling approaches. Proceedings of the 1st Int. Conf. on Debris Flow Hazards Mitigation: Mechanics, Prediction, and Assessment, ASCE, Reston, VA, USA, 576-585.

12. Rickenmann, D., Laiglec, D., Mc. Ardell, B.W., Huebl, J., (2006), Comparison of 2ddebris-flow simulation models with field events. Computers and Geosciences 10, pp241-264.

13. Shovan Lal Chattoraj.,and P.K.Champati ray (2015),Simulation and modeling of debris flows using satellite derived data: A case study from Kedarnath Area. International Journal Geomatics and Geoscience, volume 6, No 2, 2015.

14. Shovan Lal Chattoraj,and P.K. Champati ray (2018),3-Dimensional modeling of 2014-Malin Landslide, Maharashtra using satellite-derived data: A quantitative approach to numerical simulation technique. Nat Hazards Earth system science., https//doi.org/10.5194/nhess-2017-382.

15. Sosio, R., Crosta, G. B., and Hungr, O., (2008), Complete dynamic modelling calibration for the Thurwieser rock avalanche (Italian Central Alps). Engineering Geology 100, pp 11-26.

16. Tsai, M.P., Hsu, Y.C., Li, H.C., Shu, H.M., and Liu, K. F., (2011), Application of simulation technique on debris flow hazard zone delineation: a case study in the Daniao tribe, Eastern Taiwan. Natural Hazards and Earth System Sciences 11, pp 30533062 .

17. Salm, B.(1993), Flow, flow transition and runout distances of flowing avalanches. Ann. Glaciol., 18, 221-226. 
18. Schneider, D., Bartelt, P., Caplan-Auerbach, J., Christen, M., Huggel, C., and McArdell, B. W (2010), Insights into rock-ice avalanche dynamics by combined analysis of seismic recordings and a numerical avalanche model, J. Geophys. Res., 115 F04026, doi:10.1029/2010JF001734, 2010.on January 2020.

19. Voellmy A (1955) Uber die Zerstorungskraft von Lawinen. SchweizBauzeitung 73:212-285.

20. Prasad, G. V., \& Vattipalli, M. Mass Optimization for Structural Members in an Aircraft Wing Using Numerical Techniques.

21. Gara, D. K., \& Potnuru, S. Quandaries during Numerical Analysis on Shape Memory Product.

22. Shah, T., \& Tailor, M.A Numerical Solution of Laminar Flow in Porus Media with Triangular Duct by Finite Difference Method with Matlab.

23. Jeewg, M. J., Hassan, A. K. F., \& Zeboon, J. K. (2014). Experimental and numerical investigation of the dynamic characteristic of laminated composite plate hybrid with steel. Int. J. of General Eng. and Techn.(IJGET), 3, 1. 

